\title{
Effects of Aquatic Vegetation on Fish Assemblages in a Freshwater River of Taihu Lake Basin, East China
}

\author{
Jinqing Wang, Xiangfu Song ${ }^{*}$, Guoyan Zou, Wenzong Zhou \\ Eco-Environmental Protection Research Institute, Shanghai Academy of Agricultural Sciences, Shanghai, China \\ Email: *Songxfu@263.net, jinqwang@163.com
}

Received November 8, 2012; revised December 10, 2012; accepted December 17, 2012

\begin{abstract}
Distribution characteristics of fish assemblages and environmental variation in emerged plant, floating-leaved plant and blank habitats were studied. Emergent plant habitat supported the greatest fish biomass, density and body size, followed by floating-leaved plant habitat, and those of blank habitat was the lowest. Transparency of emergent plant habitat decreased during the period, but of blank habitat increased. Species number of dominant fish of emergent plant habitat compared to the others decreased from four species, i.e., Hemicculter leuciclus, Pseudobrama simoni, Carassius auratus and Ophicephalus argus in May to the single one, C. auratus in September. Those of blank habitat increased from two species, H. leuciclus and Pseudorasbora parva to four species, H. leuciclus, C. auratus, P. parva and O. argus. This result suggested that emergent plant with excessively high density could worsen habitat physical and chemical conditions, resulted in the fish's emigration to unvegetated area. Those of floating-leaved plant habitat from two species, Cultrichthys erythropterus and P. simoni, changed into four species, C. erythropterus, P. simoni, H. leuciclus and $P$. parva. The increasing structure complexity and biomass of floating-leaved macrophyte promoted the increase of dominant fish species number with seasonal change. C. auratus, C. erythropterus and H. leuciclus displayed special preferences on emergent plant, floating-leaved plant and blank habitats respectively. Fish's special habitat preference was determined by plant physical morphology, habitat characteristics and fish breeding habits.
\end{abstract}

Keywords: Macrophyte; Fish Assemblages; Emerged Plant; Floating-Leaved Plant; pH; Transparency

\section{Introduction}

Macrophytes play an important role in structuring aquatic ecosystems [1]. They serve as the major primary producer in river and lake ecosystems, providing food, foraging habitat and breeding places for aquatic organisms, maintaining the diversity and stability of aquatic organism assemblages [2,3]. Vegetations may significantly increase habitat structural complexity, potentially change biotic and abiotic processes, and provide refuges against predators for aquatic organisms [4-6]. A considerable amount of research has evaluated the close relationship of macrophyte with aquatic organisms across lake, stream and marshes [7-9].

Fish assemblages are a key component of freshwater ecosystems, being under threat worldwide [10], have significantly important relationships with macrophyte in improving water quality and ecosystem health. The change in fish community structure may cause a transition of shallow lake from a macrophyte-dominated state to a phytoplankton-dominated state due to a reduction of planktivores [11].

\footnotetext{
*Corresponding author.
}

Most of studies focus on ecological roles of submerged plants [6,12], and little attention has been paid to the information of emergent and floating-leaved species, which are abundant in eutrophic turbid water $[1,13,14]$. Emergent and floating-leaved species have relative unique morphologies compared to submerged species, and could greatly affect biotic assemblages and water quality. Yet few studies have explored the effects of different plant growth forms on fish assemblages under flowing water conditions, and further analyzing the relationships of specific environmental variable with single fish species in detail are needed.

In this study, we investigated effects of macrophytes with different growth forms on fish assemblage compared to unvegetated area, analyzed fish assemblage characteristics in different habitats. Especially, we determined the effect of seasonal variation of macrophyte characteristics on fish assemblage and species, and elucidated the relationships of water environmental variables, such as, dissolved oxygen concentration, $\mathrm{pH}$, transparency, water depth and electrical conductivity, with fish under impact of macrophyte. This study can enrich theory knowledge and relevant experimental evidences about restoring 
aquatic ecosystem in turbid water and recovering the proper self-purification capacity of river ecosystem.

\section{Materials and Methods}

\subsection{Study Site}

The experiment was conducted in Longyan River of Hudai County, Wuxi City, Jiangsu Province, China. This riverway is one of the main tributaries of Zhihugang River, the main inflow rivers of Taihu Lake. Zhihugang River is the most polluted in Taihu lake basin, water quality of their mainstream and tributaries is all inferior to class IV of environmental quality standards for surface water [9]. Major polluting components are $\mathrm{NH}_{3}-\mathrm{N}$ (ammonia nitrogen), TN (total nitrogen) and TP (total phosphorus). Longyan River connected with Zhihugang River in the east and Wujingang River in the west (Figure 1). The river is $4.3 \mathrm{~km}$ long, 50 - $100 \mathrm{~m}$ wide and $1.9-2.7 \mathrm{~m}$ in depth, which serves as an important navigable channel. When normal water level exists, Longyan River includes a wide variety of habitat types within a width of 2 to $5 \mathrm{~m}$ from river bank to the water. They are emerged plant, floating-leaved plant, submerged plant and blank habitats, respectively. The water TN in May $(4.60 \pm 0.01 \mathrm{mg} / \mathrm{l})$ and September $(3.8 \pm 0.04 \mathrm{mg} / \mathrm{l})$ were far higher than the V standard of GB3838-2002 (China Surface Water Environment Quality Standard). TP and $\mathrm{NH}_{3}-\mathrm{N}$ in May (TP: $\left.0.34 \pm 0.01 \mathrm{mg} / \mathrm{l}, \mathrm{NH}_{3}-\mathrm{N}: 1.86 \pm 0.04 \mathrm{mg} / \mathrm{l}\right)$ meeted the $\mathrm{V}$ standards, whereas they in September only meeted the IV standards (TP: $0.28 \pm 0.01 \mathrm{mg} / \mathrm{l}, \mathrm{NH}_{3}-\mathrm{N}: 1.22 \pm 0.03$ $\mathrm{mg} / \mathrm{l})$. $\mathrm{COD}_{\mathrm{Mn}}$ in both May (4.81 $\left.\pm 0.06 \mathrm{mg} / \mathrm{l}\right)$ and September $(5.08 \pm 0.07 \mathrm{mg} / \mathrm{l})$ satisfied the I standards (JQ Wang unpublished data).

\subsection{Sampling and Experimental Design}

In order to completely understand the effect of macrophyte on fish assemblages, and determine their distribution characteristics within Longyan River, a 1-km-long river reach of Longyan River close to Zhihugang River

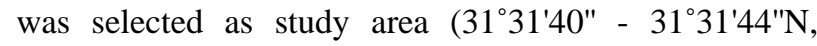
$120^{\circ} 6^{\prime} 4^{\prime \prime}$ - $120^{\circ} 6^{\prime} 33^{\prime \prime E}$, Figure 1). Three sampling points were determined in each of the three habitats (those dominated by emergent plant (EPH), by floating-leaved plant (FPH) and blank habitat $(\mathrm{BH})$ respectively) from east to west along Longyan River. Sampling points selected approximately covered several common habitat conditions of Longyan River, and could objectively reflect hydrological characteristics of this area. Samples of fish, plant and water were collected and measured respectively in May 2010 (spring) and September 2010 (summer) to elucidate the effect of aquatic macrophyte on fish assemblages and clarify several key items, that is, species composition and density of macrophyte, fish biomass and density and water physical and chemical indices.

According to the previous studies, we found it was difficult and impractical that casting nets to catch fish in dense plant area. For this reason, fish samples were collected using an electrofishing equipment, consisted of a stationary generator of alternating current (300 V, 50 - 80 Hz, 3 - 5 A, 1000 W), as detailed by Rodriguez and Lewis [10]. Each site within a $50 \mathrm{~m}$ range was single-pass electrofished for 20 seconds, and individual sampling altogether lasted 30 min. Then, the stunned fish were picked up by 5-mm-mesh dipnet when they rising to the surface. Sampled fish were placed in labeled plastic bags and fixed in $6 \%$ to $8 \%$ formalin for transport to the laboratory, and individual fish were classified, measured and weighed.

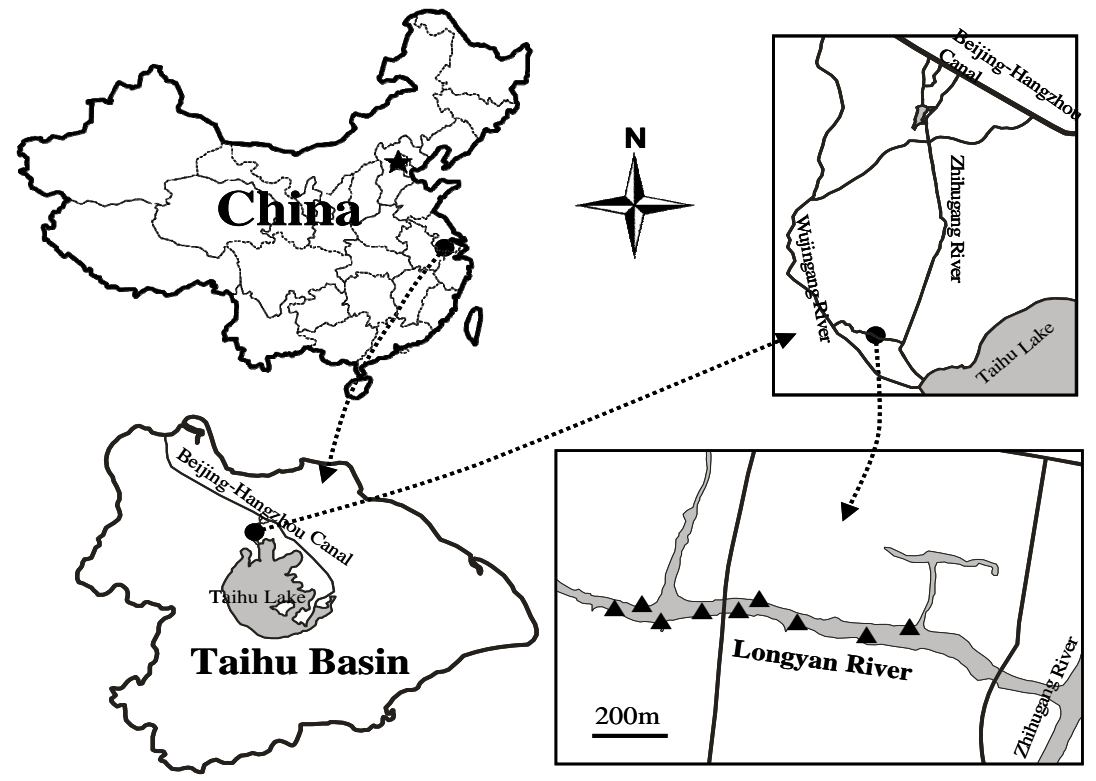

Figure 1. Schematic diagram of sampling location. Black triangles represent fish sampling sites. 
To determine the surface water characteristics in habitats, the top water at about $20-50 \mathrm{~cm}$ in depth was sampled using a Kitahara's water sampler in each position. Water transparency (TS) was measured in situ using a Secchi disc with a diameter of $30 \mathrm{~cm}$. Water dissolved oxygen (DO) at about $20-50 \mathrm{~cm}$ in depth was immediately measured by a portable oxygen analyzer (Sentry M-2, Myratek, USA). Water $\mathrm{pH}$ was measured by PHB-1 $\mathrm{pH}$ meter (Shanghai Sanxin Instrumentation, China) and electrical conductivity (EC) by DDB-1 conductivity pen meter (Shanghai Weiye Instrumentation, China). Three randomly positioned $0.25 \mathrm{~m}^{2}$ quadrats were determined in each habitat for investigating the community characteristics of emergent and floating-leaved plants.

\subsection{Data Analysis}

The effects of habitat type in each sampling month on fish assemblage characteristics (abundance, biomass, body length and weight) and water environmental variables (pH, DO, TS and EC) were examined using one-way ANOVA, followed by Tukey's post-hoc tests. Pearson correlation analyses were conducted to examine the relationships of environmental variables with fish assemblages or single species characteristics. To satisfy the assumptions of either ANOVA or correlation, data were log transformed prior to statistical analysis.

Canonical correspondence analysis (CCA) was also used to analyze the relationship between fish species and environmental variables. The original data set consisted of 14 fish species abundance and 7 environmental variables. Several environmental indices were TS, DO, water depth (WDP), pH, EC, habitat type and sampling season, respectively. Of them, habitat type and sampling season were coded with dummy variables. The environmental variables were ranked by forward selection procedure according to their explanatory capability on variation of species data, and then their significance was tested by Monte Carlo tests. Data analyses were performed using statistical packages of CANOCO 4.5 and Statistica 6.0.

\section{Results}

\subsection{Vegetation Characteristics}

Between two sampling seasons (May 2010 (spring) and late September 2010 (summer)), species composition and dominant species of plant communities are obviously different, and these seasonal changes especially impacted on fish assemblage's structure.

Emergent species were dominated by common reed Phragmites australis and wild rice grass Zizania caduciflora. In May densities of $P$. australis neonatal seedling were roughly estimated to be $40 \mathrm{ind} / \mathrm{m}^{2}$, they mixed with an equal number of litter produced last year, and Z $\mathrm{Z}$. $\mathrm{Ca}$ duciflora about $30 \mathrm{ind} / \mathrm{m}^{2}$. The height of $P$. australis was
$283 \pm 33 \mathrm{~cm}$ and Z. caduciflora $125 \pm 63 \mathrm{~cm}$. As spring and summer just was the early growth period of emergent species, current-year new $P$. australis had relatively sparse leaves, while $Z$. caduciflora leaves was still not fully expanded. Meanwhile, fresh floating-leaved plant still did not appear, but withered or decaying materials of hyacinth Eichhornia crassipes, alligator weed Alternanthera philoxenoides, crispus Potamogeton crispus and other weeds were floating on the surface of the river.

Then the biomasses of both emergent and floatingleaved plant communities significantly increased in September. The height and density of emergent species increased compared to in May. The estimated densities of $P$. australis and Z. caduciflora reached $60 \mathrm{ind} / \mathrm{m}^{2}$ and 40 ind $/ \mathrm{m}^{2}$. Their heights approximated $293 \pm 47 \mathrm{~cm}$ and 133 $\pm 17 \mathrm{~cm}$ respectively. Meanwhile, emergent plant communities interspersed with aquatic plants of other growth forms in varying amounts, such as, frogbit Hydrocharis dubia, hornwort Ceratophyllum demersum. Floatingleaved species mainly included $A$. philoxenoides, $H$. dubia and E. crassipes. Dominant species A. philoxenoides approximated $200 \mathrm{ind} / \mathrm{m}^{2}$ in density and $40 \mathrm{~cm}$ in height above the water.

\subsection{Environmental Properties}

All environmental variables showed significantly seasonal changes, of which, DO and EC in May were higher than in September. Water pH, DO, TS and EC had small differences between different habitats. Emergent plant habitat had the highest TS and EC, whereas blank water had the highest $\mathrm{pH}$ and DO content. Sampling locations was $1.01 \pm 0.40 \mathrm{~m}$ deep in May, shallower than in September $(1.19 \pm 0.43 \mathrm{~m}$ deep), and they were ca. $2.95 \pm$ $0.80 \mathrm{~m}$ away from the bank.

Water quality variation of the three habitats was different in May and September (Figure 2). Among the three habitats of May, emergent plant habitat was characterized by the lowest water $\mathrm{pH}$ and $\mathrm{DO}$, and the highest TS. Floating-leaved plant habitat had the highest $\mathrm{pH}$, median DO and TS. Blank water displayed the highest DO, lowest TS and median $\mathrm{pH}$. While in September emergent plant habitat showed the highest $\mathrm{pH}$, lowest TS and median DO, floating-leaved plant habitat was characterized by the lowest pH, DO and median TS, and blank habitat displayed slightly high DO, TS and median pH. Both in May and September, water EC in the three habitats had not significant difference. These results comprehensively showed water environmental status of the three habitats in two sampling periods, respectively.

\subsection{Fish Assemblage Characteristics}

Results showed that Hemicculter leuciclus had the greatest density, followed by Pseudobrama simoni, Carassius 
auratus, Cultrichthys erythropterus, Pseudorasbora parva (Figures 3(a) and (b)). Dominant species in order of biomass were ranked as C. auratus, $H$. leuciclus, $P$. simoni, C. erythropterus, Ophicephalus argus (Figures 3(c) and (d)).

Emergent plant habitat in May possessed the highest total fish density and biomass among the three habitats, yet the densities of species $H$. leuciclus, C. auratus and $P$. simoni and the biomasses of $C$. auratus, $H$. leuciclus, $P$. simoni and $O$. argus in emergent plant habitat were also the highest. Meanwhile, total fish density and biomass of floating-leaved plant habitat were between those of the other two habitats. The density and biomass of $C$. erythropterus in this habitat were the highest and those of $H$. leuciclus lowest compared with the other two habitats. The densities of $P$. simoni between in emergent and floating-leaved plant habitats almost had no difference, as well as the biomass of $\mathrm{H}$. leuciclus in emergent plant habitats was close to those in blank habitats. Those of blank habitats were the lowest, but density of $P$. parva (ANOVA: $F_{2,4}=13.18, p<0.02$ ) and biomass of $\mathrm{H}$. leuciclus were higher than those of the other two habitats.
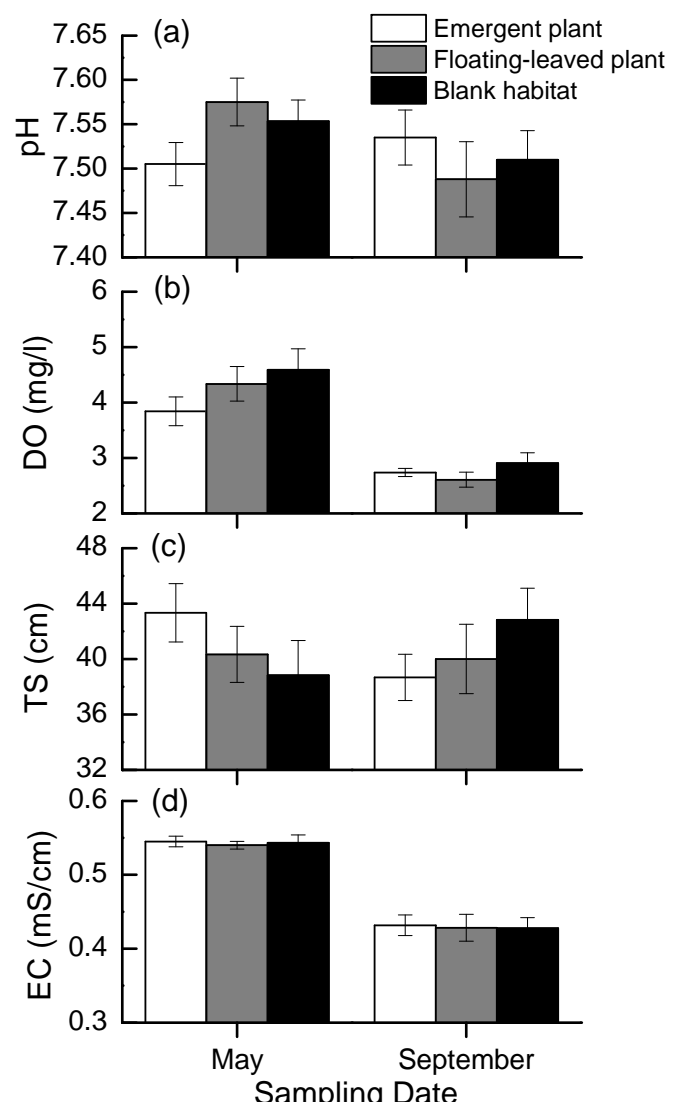

Figure 2. Effects of aquatic higher plants (emerged plants, floating-leaved plants and blank habitats) on water quality indices in Longyan River in May and September. (a) pH; (b) Dissolved Oxygen (DO); (c) Transparency (TS); (d) Electrical Conductivity (EC).
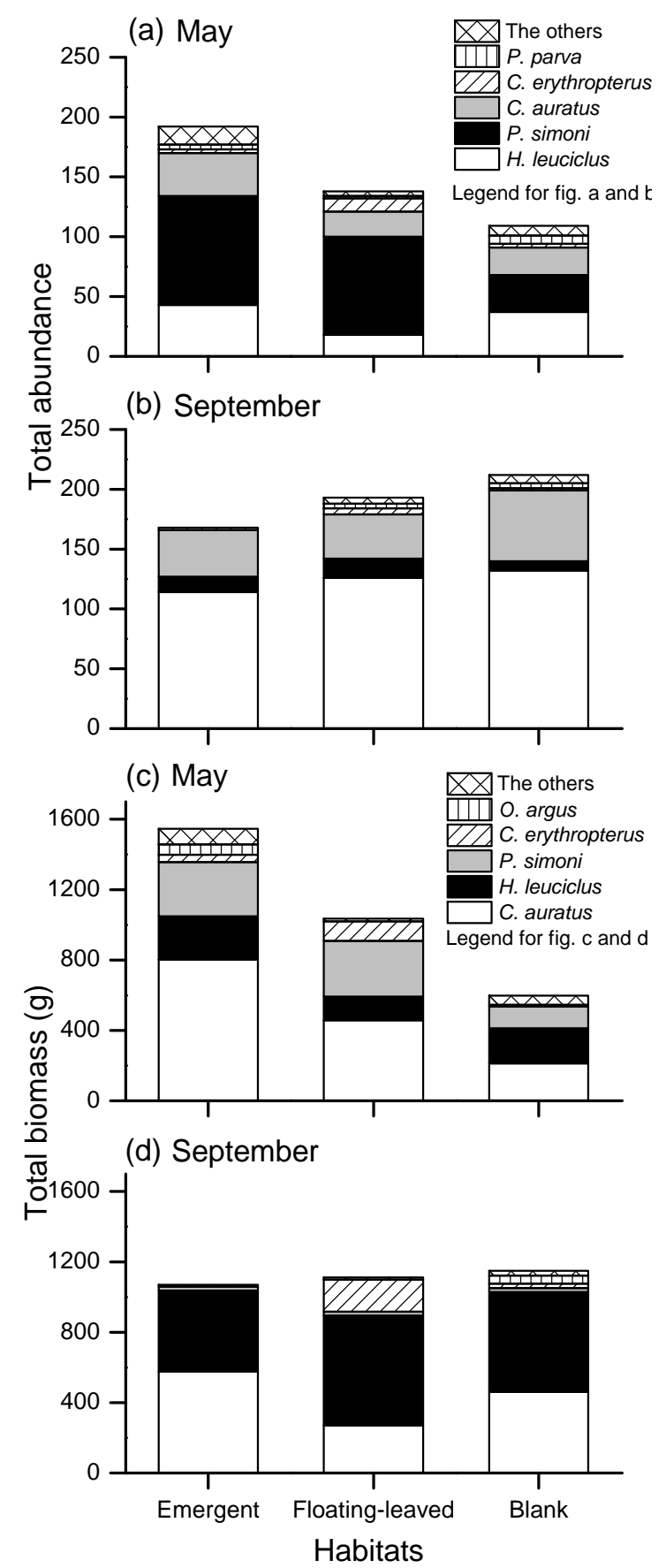

Figure 3. Comparison of total abundance and biomass of dominant fish species between three habitats in each sampling date. (a,b) Total abundance in May and September; (c,d) Total biomass in May and September.

In September total abundance and biomass between the three habitats had a minor difference, the highest in blank habitat and lowest in emergent plant habitat. However, the species composition were significant different between them: 1) The densities of C. auratus, H. leuciclus and P. parva, as well as the biomasses of $\mathrm{H}$. leuciclus and $O$. argus, in blank habitat were higher than 
those in the other habitats; 2 ) The densities of $P$. simoni (ANOVA: $F_{2,8}=6.44, p<0.02$ ) and $C$. erythropterus, as well as the biomasses of $H$. leuciclus, C. erythropterus (ANOVA: $F_{2,3}=12.40, p<0.04$ ) and $P$. parva (ANOVA: $\left.F_{1,3}=12.00, p<0.04\right)$, in floating-leaved plant habitat were the highest among the three habitats. Remarkably, C. auratus density of emergent plant habitat was the highest among the three habitats in spite of their slightly low total fish density.

Fish body weights and full length had similar difference between three habitats. Fish mean body size were the greatest in emergent plant habitat and least in blank habitat (full length: $F_{2,33}=1.784, p=0.18$; body weight: $\left.F_{2,33}=4.004, p<0.05\right)$. The full length and weight of crucian carp $C$. auratus were the greatest in emergent plant habitat and least in blank habitats (full length: $F_{2}$, $154=5.15, p<0.01$; weight: $F_{2,154}=5.23, p<0.01$ ). While redfin culter $C$. erythropterus in floating-leaved plant habitats was the greatest and least in blank habitat (full length: $F_{2,23}=4.04, p<0.05$; weight: $F_{2,23}=2.99, p<$ 0.05). The two parameters of Acanthorhodeus macropterus were also the largest in emergent plant habitat and least in floating-leaved plant habitats (full length: $F_{2,5}=$ 11.75, $p<0.01$; weight: $\left.F_{2,5}=7.16, p<0.05\right)$.

Correlation analysis results showed that fish length was negatively correlated with DO and EC, and body weight negatively correlated with $\mathrm{pH}$ and DO (Table 1).
Both density and biomass of $H$. leuciclus were significantly negatively correlated with DO and EC, whereas both density and biomass of $P$. simoni were positively correlated with DO and EC. Similarly, those of Rhinogobius giurinus were positively correlated with DO and TS. $P$. parva biomass had positive correlations with EC. In addition, C. erythropterus density was significantly positively correlated with $\mathrm{pH}$ and $\mathrm{DO}$, and its biomass was correlated with water depth (WDP) as well (Table 1).

The environmental variables had a significant association with both species abundance and biomass of fish assemblage (Monte Carlo permutation tests, $\mathrm{n}=499, \mathrm{p}<$ 0.01 , Table 2). CCA based on the species density indicated that the first two axes accounted for $28.1 \%$ of the variation in species data and $80 \%$ of the variation in species-environment relationship, and species biomass dataset showed that the first two axes accounted for $28 \%$ of the variation in species data and $74 \%$ of the variation in species-environment relationship. As mentioned above, the two CCA biplots based on fish density and biomass datum of two sampling dates also presented assemblage characteristics and environmental properties in different habitats and sampling dates in detail (Figures 4(a) and (b)). The distance between species points and centroids of dummy variables (habitat type and season) implied the relative total abundances of the species in particular habitat (summed over all the samples in the habitat).

Table 1. Pearson's correlation coefficients of fish assemblages and species characteristics with water environment variables. “*” indicated $p<0.05$.

\begin{tabular}{|c|c|c|c|c|c|c|}
\hline \multicolumn{2}{|c|}{ Fish assemblage and species characteristics } & WDP & $\mathrm{pH}$ & DO & TS & EC \\
\hline \multirow{4}{*}{ Assemblage characteristics } & Total density & 0.08 & 0.24 & 0.02 & 0.06 & -0.08 \\
\hline & Total biomass & 0.07 & 0.11 & 0.07 & 0.12 & 0.07 \\
\hline & Full length & 0.07 & -0.11 & $-0.39^{*}$ & 0.03 & $-0.36^{*}$ \\
\hline & Weight & -0.14 & $-0.31^{*}$ & $-0.38^{*}$ & 0.08 & -0.30 \\
\hline \multirow{3}{*}{ Species density } & H. leuciclus & 0.16 & -0.07 & $-0.49^{*}$ & -0.03 & $-0.63^{*}$ \\
\hline & P. simoni & -0.02 & 0.31 & $0.41^{*}$ & 0.05 & $0.38^{*}$ \\
\hline & C. erythropterus & 0.14 & $0.40^{*}$ & $0.37^{*}$ & 0.22 & 0.18 \\
\hline \multirow{5}{*}{ Species biomass } & H. leuciclus & 0.28 & -0.14 & $-0.44^{*}$ & 0.06 & $-0.57^{*}$ \\
\hline & P. simoni & -0.03 & 0.31 & $0.44^{*}$ & 0.05 & $0.41^{*}$ \\
\hline & C. erythropterus & $0.40^{*}$ & 0.22 & 0.10 & 0.07 & -0.01 \\
\hline & $R$. giurinus & -0.12 & 0.24 & $0.40^{*}$ & $0.33^{*}$ & 0.20 \\
\hline & P. parva & -0.01 & 0.04 & 0.30 & -0.03 & $0.34^{*}$ \\
\hline
\end{tabular}

Table 2. Summary statistics for canonical correspondence analysis (CCA) based on fish density and biomass data matrices in Longyan River in 2010.

\begin{tabular}{|c|c|c|c|c|}
\hline & \multicolumn{2}{|c|}{ Fish density } & \multicolumn{2}{|c|}{ Fish biomass } \\
\hline & Axis 1 & Axis 2 & Axis 1 & Axis 2 \\
\hline Eigenvalue & 0.325 & 0.073 & 0.200 & 0.151 \\
\hline Species-environment correlations & 0.870 & 0.583 & 0.788 & 0.797 \\
\hline \multicolumn{5}{|l|}{ Cumulative percentage variance } \\
\hline Species data & 22.9 & 28.1 & 15.9 & 28.0 \\
\hline Species-environment relation & 65.3 & 80.0 & 42.2 & 74.0 \\
\hline Sum of all eigenvalues & \multicolumn{2}{|c|}{1.417} & \multicolumn{2}{|c|}{1.255} \\
\hline \multicolumn{5}{|l|}{ Summary of Monte Carlo test } \\
\hline First canonical axis & \multicolumn{2}{|c|}{$F=8.028(p<0.01)$} & \multicolumn{2}{|c|}{$F=5.118(p<0.01)$} \\
\hline All canonical axes & \multicolumn{2}{|c|}{$F=1.827(p<0.01)$} & \multicolumn{2}{|c|}{$F=2.051(p<0.01)$} \\
\hline
\end{tabular}


In term of the impact extent of environmental factor on species density composition, they were ranked from high to low as May, September, DO, EC, pH, BH, FPH, TS, WDP, EPH. According to forward selection procedure and Monte Carlo permutation tests from CCA, several variables (DO, WDP, EC, TS, $\mathrm{pH}$ and dummy variables for habitat type and sampling season) totally explained $50 \%$ of the total variation in assemblage density composition. Also, CCA analysis results based on fish biomass matrix showed that, environmental variables from high to low according to impact intensity of environmental factor were DO, May, September, EC, pH, WDP, FPH, EPH, $\mathrm{BH}, \mathrm{TS}$. Variables retained through forward selection procedure totally explained $47 \%$ of the total variation in assemblage composition.

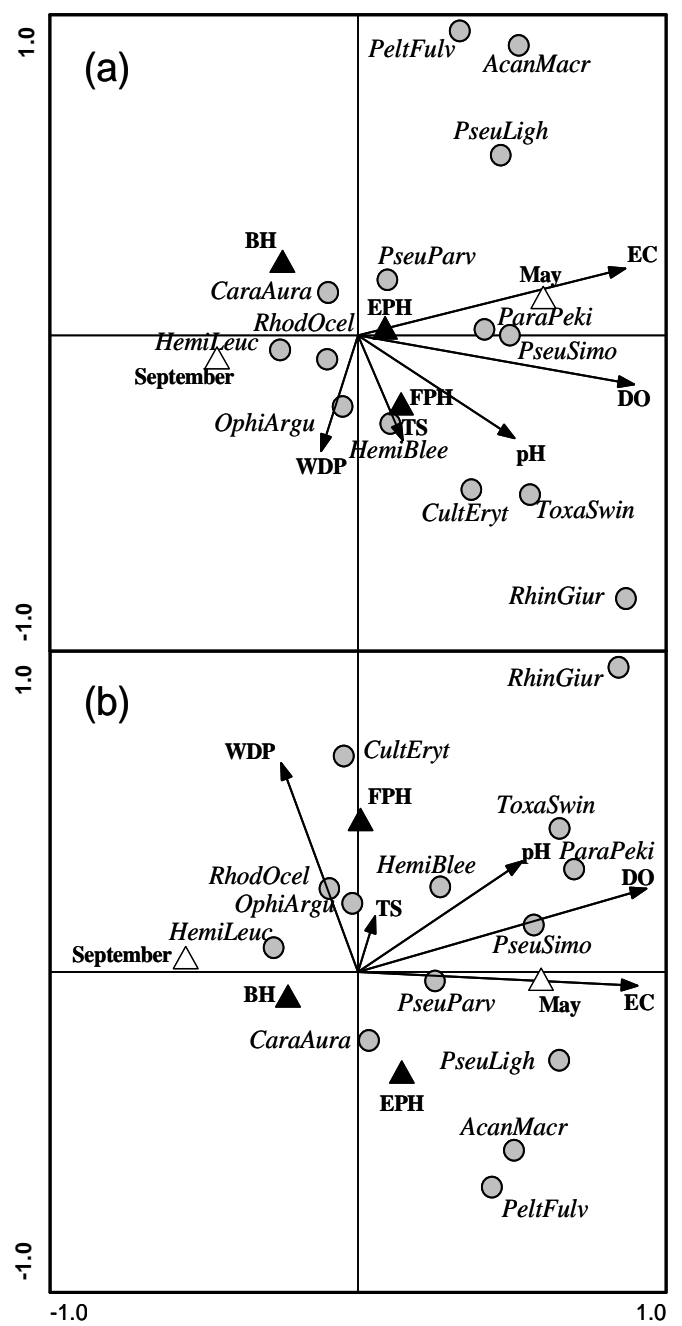

Figure 4. CCA biplots of fish assemblages and environmental variables in Longyan River based on (a) fish density and (b) biomass. Fish are identified by the first four letters of genus and species. Black triangles indicated three habitat types. EPH, FPH and BH represented Emergent plant habitat, Floating-leaved plant habitat and Blank habitat, respectively. White triangles indicated two sampling dates.
Among several dominant fish species, both the relative density and biomass of $C$. erythropterus were the highest in floating-leaved plant compared to the other two habitats (Figures 4(a) and (b)). In addition, the density and biomass of $P$. simoni in two plant habitats were higher than those in blank habitat. Meanwhile, emergent plant habitat had the highest biomass in C. auratus. Nevertheless, the blank water had the highest densities in $H$. leuciclus and C. auratus and the highest biomass in H. leuciclus.

The density and biomass of $P$. simoni, $P$. pekinensis peaked in high DO and EC areas, and those of H. leuciclus peaked in low DO and EC areas (Figures 4(a) and (b)). The highest density of $O$. argus and the highest biomasses of both C. erythropterus and R. ocellatus occurred in deep water area, whereas the density of $P$. parva and biomasses of both $C$. auratus and A. macropterus peaked in shallow water area. The densities and biomasses of $C$. erythropterus and $R$. giurinus peaked in areas with high $\mathrm{pH}$, DO and TS, and C. auratus peaked in areas with low indices. Above results were approximately consistent with correlation analysis. Furthermore, CCA result of fish density and biomass had similar conclusions.

\section{Discussion}

\subsection{Characterizing Fish Assemblage and Environmental Properties of Different Habitats}

In the current study, fish assemblage characteristics and species composition in emergent, floating-leaved plants and blank habitats had obvious differences in this study. These results implied physical and chemical factors and aquatic macrophyte significantly influenced fish community. Macrophytes have been considered important in maintaining diversity and stability of various aquatic communities [2-5], for example, increasing structural complexity of habitat [3], providing refuge and protecting fish from predators and harsh environment [14,15], and supplying abundant food resource [2]. CCA results indicated DO, pH, TS and macrophyte were key environmental variables and played important roles in determining species composition of fish assemblages. Several studies have found oxygen concentration, predation and food availability are all influenced by macrophytes $[2,4]$. Aquatic plant community by the photosynthesis constructs diverse habitat conditions with various oxygen and temperature conditions, meeting different demands of fish community.

Remarkably, due to the difference of their physical morphologies between emergent and floating species, the two types of plants had different structural complexity and distinct effects on river hydrological characteristics, and meanwhile exerted completely differential influences 
on fish [16]. In this study, emergent plant area had high TS yet floating-leaved species relative low. From the plant community characteristics point of view, emergent plants mainly occurred in nearshore shallow water, were dominated by $P$. australis and $Z$. caduciflora. These plants reached over $1 \mathrm{~m}$ in height above water surface, keeping their canopy over the water and dense strong stems standing upright in water. The dense stems of emergent species could greatly decrease flow velocity, so which reduce the transportation capability of water flow on fish assemblage and elevate fish feeding efficiency [16,17].

In contrast, floating-leaved species drifted with $30 \mathrm{~cm}$ in plant height above the water. Obviously, emergent species had much higher biomass and structural complexity compared to floating-leaved species. Dense vegetation possesses excellent shading effect, ameliorating habitat conditions for fish through decreasing water temperature [18]. Plant roots, stems and leaves efficiently attracting aquatic insects and promoting colonization of eriphyton, are excellent habitats for benthivorous and entomophagous fish as increasing prey availability $[16,17]$. Consequently, as expected, we found emergent plant habitat supported the greatest fish biomass, fish density and body size, followed by floating-leaved plant habitat. Open water had relatively high flow velocity and water quality but lacked refuge and food resource, hence where fish was low in density and biomass.

On the other hand, fish habitat preferences significantly varied as species changed, and each habitat always attracted own faithful resident. For instance, C. auratus had a persistent preference on emergent plant habitat irrespective of season. C. erythropterus always selected floating-leaved plant community as its own habitat. $H$. leuciclus mainly inhabited no-plant water area. Further, $P$. simoni displayed a special preference on the two plant habitats. This selectivity was apparent to be determined by habitat characteristics and fish live habit together, also associated with fish feeding habits. Meerhoff [1] reports similar results. This result provides evidence that good habitat had relativity and that of high biodiversity was not always suitable for all species.

\subsection{Seasonal Changes of the Effects of Macrophytes on Fish Assemblages}

Species composition, community characteristics and physical environment of emergent and floating-leaved plant communities varied as the season progressed, which correspondingly altered fish assemblage's characteristics of each habitat. Emergent species just began to grow in May. At this time, new seedling of $P$. australis had relatively sparse leaves yet the leaves of $Z$. caduciflora were not fully expanded. No fresh floating-leaved plant was found in littoral area. However by September, the height, density and biomass of both emergent and float- ing species were significantly elevated and floating species involving four species flourished with $40 \mathrm{~cm}$ in height above water.

The improvements of aquatic macrophyte on water quality, such as, TS and EC, have been frequently mentioned $[10,15]$; also, their functions are significantly affected by plant growth forms $[13,19]$. For water properties in this study, $\mathrm{pH}$ order of emergent plant habitat changed from the lowest to the highest among the three habitats. Contrarily, its TS order decreased from the highest to the lowest. Additionally, $\mathrm{pH}$ of floating-leaved plant habitat was reduced but TS of blank habitat increased during the period. These variations could be tightly associated with decomposition of plant litters and the increase of new seeding. In May emergent species possessed a large amount of litters, and both plant fresh tissues and litters possibly had significant roles on decreasing water nutrients and depositing suspended particles, thus increasing water TS. Meanwhile, emergent species had intermediate densities of plant and litters, providing organic detritus as food and refuge to buffer temperature for aquatic organisms. By September, plant litters was largely decomposed and plant flourished in Longyan River. Flow velocity and water TS were decreased in succession due to increasing plant density and following metabolism.

It is obvious that with plant's growth, fish assemblage activities in plant community were impeded by dense plant. More and more fish emigrated from plant community to the blank waters for feeding and habiting in September, which induced that fish amount of emergent species slightly decreased compared to blank area. Dominant habitat in terms of fish harboring capacity accordingly changed from emergent plant to blank habitat during the period. Although macrophyte with intermediate density plays an important role in improving habitat condition and facilitating biotic colonization, excessively high or low plant density resulted in the adverse effect on environment and fish assemblage. This conclusion was supported by a great deal of studies [4,7,8]. Emergent plant with excessively high density brought deteriorated physical and chemical conditions for fish, resulted in the fish's emigration to unvegetated area.

On the other hand, dominant fish species of emergent plant compared to the other habitats also shifted from four species, i.e., H. leuciclus, P. simoni, C. auratus and $O$. argus in May to the single one, C. auratus in September. In contrast, those of blank habitat increased from two species, $H$. leuciclus and $P$. parva to four species, $H$. leuciclus, C. auratus, $P$. parva and $O$. argus in this study. The reduction of dominant fish species in emergent species could be explained as mentioned in above paragraph. Those of floating-leaved plant from two species, C. erythropterus and P. simoni in May, changed into four species, C. erythropterus, $P$. simoni, $H$. leuciclus and $P$. 
parva in September. Obviously, the height, density and biomass of floating-leaved species peaked in September, and they formed dense vegetation on the water surface, increasing habitat complexity and suitability. Fish harboring capacity of plant habitats increases with their density, biomass and thereby structural complexity $[3,10,20]$. Plant physical morphology has large effect on their fish harboring capacity, and aquatic plants with complex leaf arrangements had a greater fish harboring capacity than had simple forms [7,14,20]. Consequently, the increasing structure complexity and biomass of floating-leaved macrophyte promoted the increase of dominant fish species number with seasonal change.

\subsection{Distribution Characteristics and Life Habits of Dominant Fish}

The response of fish assemblage to aquatic macrophytes significantly varied according to breeding and living habits of fish species as well. The remarkable differences of fish assemblages in macrophyte habitats are mostly attributed to the influence of macrophyte on predation risk and food availability [14]. Yet, species, body size and feeding habits also determined fish habitat selectivity [1].

C. erythropterus is a fast-swimming carnivorous species, good at preying on the slow-swimming benthivorous species, such as $P$. simoni. The fish usually inhabit lushly vegetated area during their breeding period, and select fine roots of floating-leaved species (A. philoxenoides and Trapa bicornis) or stem and leaves of submerged species for spawning substrate [21]. Not only do floating-leaved species show significant shading and cooling functions when spreading on the water surface, but also they facilitate fish's swimming due to their sparse and tender stems. We found C. erythropterus exhibited an especial preference for floating-leaved species. Additionally, Meerhoff points out fish feeding habits especially determined their selectivity for different macrophyte [1], and dominant omnivore-planktivores preferred submerged plants but omnivore-piscivores selected floating-leaved plants [1]. We can infer that fish living and breeding habits largely influenced their special selectivity for different habitats as season changed.

As Xie (1986) suggests [22], H. leuciclus is a omnivorous species, positively feeding animal food, moving quickly and aggregately swimming in water of higher layer. May to June is suitable breeding season for H. leuciclus. Hence, flowing water is considered as the suitable habitat for growing of $H$. leuciclus. Our results showed that the fish mostly inhabited emergent plant and blank habitats in May and blank habitat in September. We suggest that the fish dived into plant community for foraging and spawning during breeding season, while nonbreeding season feeding in open area without plant. As mentioned in part 2 of discussion, benthic fish $P$. simoni was distributed in both emergent and floating-leaved habitats in May but only in floating-leaved plant community in September. This fish usually inhabited middle and lower layers of water, usually spawning in May to June and mostly feeding on periphyton and detritus of macrophyte [21]. This breeding and feeding habits of $P$. simoni determined the distribution patterns in May and September.

Compared to the other habitats, the density, biomass and body size of $C$. auratus in emergent plant habitat were the highest during both experimental period. This implied that $C$. auratus had a special preference for emergent species. Previous studies point out their breeding season lasted from March to August, and the breeding activity is the most active in May. Here, a great amount of $C$. auratus spawns in shallow water area with dense emergent plants, soft bottom and high TS. Fish eggs easily adhere to stems or leaves of aquatic plants or other objects [21]. Similarly, Kobayashi also found aquatic plants can significantly promote the spawning behaviour of goldfish and crucian carp [23]. Most fish (e.g., P. simoni, C. erythropterus and $R$. giurinus) dwelled in highquality water (i.e., high DO, high TS), and only H. leuciclus and C. auratus in poor-quality water with low $\mathrm{pH}$, DO and TS, which implied that this species possessed high tolerance to polluted water. H. leuciclus and C. auratus had obvious competition advantages when they feeding, refuge and breeding in eutrophic water compared to the other species.

\section{Conclusion}

Fish's special habitat preference was determined by plant physical morphology, habitat characteristics, fish living and breeding habits. Plant density, biomass and habitat quality of different plant growth forms varied as season changed, which altered their impacts on special fish species involving many aspects of fish community, such as, survival, feeding, inhabit and breeding characteristics. This study could help us to understand the function difference of various plant growth forms on fish assemblage and their interaction. Rigorous manipulation experiment is needed in future to further evaluate the special effects of aquatic plant morphology, plant properties, and flow status on fish. Only scientifically regulating species composition and growth of aquatic macrophyte and exerting their positively roles in structuring fish community, can we restore and maintain healthy wholesome aquatic ecosystem, protect, conserve and enhance biodiversity of freshwater fish.

\section{Acknowledgements}

This study was financially supported by National Water Pollution Control and Management Technology Major 
Projects of China (Grant No. 2009ZX07101) and National Natural Science Foundation of China (Grant No. 30821140542).

\section{REFERENCES}

[1] M. Meerhoff, N. Mazzeo, B. Moss and L. RodríguezGallego, "The Structuring Role of Free-Floating versus Submerged Plants in a Shallow Subtropical Lake,” Aquatic Ecology, Vol. 37, No. 4, 2003, pp. 377-391. doi:10.1023/B:AECO.0000007041.57843.0b

[2] A. A. Agostinho, S. M. Thomaz, L. C. Gomes and S. Baltar, "Influence of the Macrophyte Eichhornia azurea on Fish Assemblage of the Upper Parana River Floodplain (Brazil),” Aquatic Ecology, Vol. 41, No. 4, 2007, pp. 611619. doi:10.1007/s10452-007-9122-2

[3] S. M. Thomaz, E. D. Dibble, L. R. Evangelista, J. Higuti and L. M. Bini, "Influence of Aquatic Macrophyte Habitat Complexity on Invertebrate Abundance and Richness in Tropical Lagoons," Freshwater Biology, Vol. 53, No. 2, 2008, pp. 358-367.

[4] L. E. Miranda, M. P. Driscoll and M. S. Allen, "Transient Physicochemical Microhabitats Facilitate Fish Survival in Inhospitable Aquatic Plant Stands,” Freshwater Biology, Vol. 44, No. 4, 2000, pp. 617-628. doi:10.1046/j.1365-2427.2000.00606.X

[5] F. Pelicice, A. A. Agostinho and S. M. Thomaz, "Fish Assemblages Associated with Egeria in a Tropical Reservoir: Investigating the Effects of Plant Biomass and Diel Period,” Acta Oecologica, Vol. 27, No. 1, 2005, pp. 9-16. doi:10.1016/j.actao.2004.08.004

[6] C. Phiri, A. Chakona and J. A. Day, “Aquatic Insects Associated with Two Morphologically Different Submerged Macrophytes, Lagarosiphon ilicifolius and Vallisneria aethiopica, in Small Fishless Ponds,” Aquatic Ecology, Vol. 45, No. 3, 2011, pp. 405-416. doi:10.1007/s10452-011-9363-y

[7] J. M. Caffrey, “Aquatic Plant Management in Relation to Irish Recreational Fisheries Development,” Journal of Aquatic Plant Management, Vol. 31, 1993, pp. 162-168.

[8] O. J. Ferrer-Montano and E. D. Dibble, “Aquatic Plant Densities and Larval Fish Abundance in Vegetated Habitats on the Tennessee-Tombigbee Waterway System," Journal of Freshwater Ecology, Vol. 17, No. 3, 2002, pp. 455-460. doi:10.1080/02705060.2002.9663920

[9] J. Q. Wang, X. F. Song, F. X. Liu, G. Y. Zou, Z. S. Fu, C. E. Liu, Y. Q. Liu, Q. Pan and Z. D. Sun, "Fish Assemblage Status in Longyanhe River System, Tributary of Zhihugang, Taihu Basin,” Journal of Lake Science, Vol. 23, No. 6, 2011, pp. 982-990.

[10] M. A. Rodriguez and W. M. Lewis, "Structure of Fish Assemblages along Environmental Gradients in Floodplain Lakes of the Orinoco River,” Ecological Monographs, Vol. 67, No. 1, 1997, pp. 109-128. doi: $10.2307 / 2963507$

[11] C. Bronmark and S. E. B. Weisner, "Indirect Effects of Fish Community Structure on Submerged Vegetation in Shallow, Eutrophic Lakes: An Alternative Mechanism,”
Hydrobiologia, Vol. 243, No. 1, 1992, pp. 293-301. doi:10.1007/BF00007045

[12] L. P. Rozas and W. E. Odum, “Occupation of Submerged Aquatic Vegetation by Fishes: Testing the Roles of Food and Refuge,” Oecologia, Vol. 77, No. 1, 1988, pp. 101106. doi:10.1007/BF00380932

[13] M. Cazzanelli, T. P. Warming and K. S. Christoffersen, "Emergent and Floating-Leaved Macrophytes as Refuge for Zooplankton in a Eutrophic Temperate Lake without Submerged Vegetation,” Hydrobiologia, Vol. 605, No. 1, 2008, pp. 113-122. doi:10.1007/s10750-008-9324-1

[14] A. A. Padial, S. M. Thomaz and A. A. Agostinho, "Effects of Structural Heterogeneity Provided by the Floating Macrophyte Eichhornia azurea on the Predation Efficiency and Habitat Use of the Small Neotropical Fish Moenkhausia sanctaefilomenae," Hydrobiologia, Vol. 624, No. 1, 2009, pp. 161-170. doi:10.1007/s10750-008-9690-8

[15] M. Scheffer, "The Effect of Aquatic Vegetation on Turbidity: How Important Are the Filter Feeders,” Hydrobiologia, Vol. 408-409, 1999, pp. 307-316. doi:10.1023/A:1017011320148

[16] M. P. Marchetti and P. B. Moyle, "Effects of Flow Regime on Fish Assemblages in a Regulated California Stream,” Ecological Applications, Vol. 11, No. 2, 2001, pp. 530-539. doi:10.1890/1051-0761(2001)011[0530:EOFROF]2.0.CO ;2

[17] J. E. Argentina, M. C. Freeman and B. J. Freeman, “The Response of Stream Fish to Local and Reach-Scale Variation in the Occurrence of a Benthic Aquatic Macrophyte," Freshwater Biology, Vol. 55, No. 3, 2010, pp. 643-653. doi:10.1111/j.1365-2427.2009.02301.x

[18] D. E. Shoup and D. H. Wahl, "Fish Diversity and Abundance in Relation to Interannual and Lake-Specific Variation in Abiotic Characteristics of Floodplain Lakes of the Lower Kaskaskia River, Illinois,” Transactions of the American Fisheries Society, Vol. 138, No. 5, 2009, pp. 1076-1092. doi:10.1577/T07-272.1

[19] S. De Backer, S. Van Onsem and L. Triest, "Influence of Submerged Vegetation and Fish Abundance on Water Clarity in Peri-Urban Eutrophic Ponds,” Hydrobiologia, Vol. 656, No. 1, 2010, pp. 255-267. doi:10.1007/s10750-010-0444-Z

[20] D. M. Warfe and L. A. Barmuta, "Habitat Structural Complexity Mediates Food Web Dynamics in a Freshwater Macrophyte Community,” Oecologia, Vol. 150, No. 1, 2006, pp. 141-154. doi:10.1007/s00442-006-0505-1

[21] Y. Ni and C. D. Zhu, "Fishes of Taihu Lake," Shanghai Scientific and Technical Publishers, Shanghai, 2005.

[22] Z. Y. Xie, X. F. Wu, L. H. Zhuang and D. S. Li, "Investigations of the Biology of Hemiculter leucisculus in Fenhe Reservoir," Journal of Shandong College of Oceanology, Vol. 16, No. 4, 1986, pp. 54-69.

[23] M. Kobayashi, H. Kuroyanagi, S. Otomo and Y. Hayakawa, "Involvement of Aquatic Plants in the Spawning Behaviour of Goldfish and Crucian Carp," Cybium, Vol. 32, No. 2, 2008, pp. 310-311. 